\title{
Application of Landscape Sculpture in Interior Design-Taking Wood Carving as an Example
}

\author{
Chaoyi You' ${ }^{1}$ Jingsi $\mathrm{Li}^{2}$ \\ ${ }^{1}$ Architecture and Urban Planning College of Southwest Minzu University, Chengdu, China \\ ${ }^{2}$ Art College of Southwest Minzu University, Chengdu, China \\ Email:651645399@qq.com
}

How to cite this paper: You, C.Y. and Li, J.S. (2020) Application of Landscape Sculpture in Interior Design-Taking Wood Carving as an Example. Open Access Library Journal, 7: e6709.

https://doi.org/10.4236/oalib.1106709

Received: August 12, 2020

Accepted: August 24, 2020

Published: August 27, 2020

Copyright $\odot 2020$ by author(s) and Open Access Library Inc.

This work is licensed under the Creative Commons Attribution International License (CC BY 4.0).

http://creativecommons.org/licenses/by/4.0/ (c) (i) Open Access

\begin{abstract}
With the sublimation of art, people have a recognition of "beauty" and worship of "nature", so they spread natural elements in all details and some decorations in interior design, and endowed with commemorative, thematic, decorative, functional and furnishing features shown in landscape sculpture. The furnishing, also known as the shelf sculpture, takes the landscape sculpture as the main body to fully expand the scope and possibility of landscape sculpture, and show the artist's ideas, styles, feelings, personality, and even more in a larger space. Therefore, the author puts forward the following two stages, fit and breakthrough. The wood carving technology is applied to all aspects of interior design, so as to show the unique and lasting inheritance and development significance of the technics full of traditional culture in the interior design.
\end{abstract}

\section{Subject Areas}

Architecture, Art

\section{Keywords}

Chinese Tradition, Interior Design, Wood Carving, Possibility, Application

\section{Introduction}

In addition to reflecting the spirit of the craftsman, the exquisite Chinese traditional handicraft shows the artistic style of generations and the traditional crafts with thousands of years of history. In the era when there was no information technology, everything originated from nature and returned to nature, started 
from nature and surpassed nature, originated from the wealth of the earth and created as the art of the earth. "Nature", the soul of landscape design, can be carved into a landscape sculpture which is harmonious and unified with nature by the hands of craftsmen. It's the key action to display the natural elements in nature with different aesthetic and art.

Because sculpture is a three-dimensional art form, only by dynamic observation can the appreciator obtain information from the space, shape, volume, feeling, color and so on when appreciating the sculpture [1]. The process of artistic expression often comes from artistic intuition. Sculptors always strive to combine body and soul together. They try to express the soul they give to the body by different means, different ways and different materials. As a result, sculptures of different materials are produced, including metal sculpture, stone sculpture, resin sculpture, sandstone sculpture, gypsum sculpture, clay sculpture, traditional cement sculpture, wood sculpture, etc., among which wooden sculpture is more outstanding in China's traditional crafts. Wood carving, as a traditional culture and art, is called "folk craft". With its ingenious conception, careful design and gorgeous decoration, wood carving technology makes interior design full of ancient flavor in Chinese traditional culture, so that the style is favored by the public and widely used in modern interior decoration. The reason why people love wood carving, a traditional Chinese art form, is that wood carving has the most primitive natural attributes. At the same time, the traditional aesthetic feeling of wood carving can meet people's aesthetic needs from the visual point of view.

Nowadays, under the background of various interior decoration styles, interior designers need to solve how to better apply the wood carving elements in landscape sculpture to modern indoor environment art design, which is the goal that the experts and designers are pursuing. At the same time, more and more scholars began to pay attention to the research. According to the latest research in 2020, Chen Gaojie [2] and Hong Liangliang [3] carried out the research on the application of local wood carving in the interior design. What's more, Luo Haowei [4], Shi Lei [5] and Song Xinglin [6] explored the application of traditional wood carving in interior design. Among them, the greater test faced by interior designers is how to combine traditional wood carving elements with modern design techniques to present a landscape sculpture more in line with the aesthetic of modern people. As the fusion of traditional craft and artistic conception with modernization, this kind of new design expression is the comprehensive expression of natural artistic conception, humanistic artistic conception and artistic conception.

\section{From Fit to Breakthrough}

Fit is conformance [7]. In addition to accord with the interior design style, the different woodcarving works should break through the traditional limitation, and show different connotation and meanings aiming at the specific design. 


\subsection{Fit in with Interior Space Style and Inherit Chinese Traditional Decoration}

First of all, in addition to inheriting Chinese traditional culture, the application of Chinese traditional decorative wood carving also retains excellent traditional culture. The development of modern interior design in China is closely related to the strong influence of traditional Chinese culture. Many mature and valuable traditional cultural elements left by Chinese predecessors to modern people are fully utilized by interior designers. The figures, animals, plants, utensils, mountains, water, clouds, and legendary auspicious animals such as dragons, phoenixes and unicorns in each traditional wood carving work can form a beautiful wood carving decorative pattern. To a large extent, the rich and diverse wood carving patterns have been endowed with strong vitality, which makes them more artistic and ornamental.

The theme and expression of wood carving technology in modern indoor home have been better innovated. At the same time, different specifications, patterns, colors, themes of wood carvings meet the needs of different owners to a large extent. These wood carving techniques, which are full of novelty, individuality, modernity, fashion and auspicious implication, add a sense of corner and space that can be understood and felt for home decoration, and also express a longing for the natural environment.

\subsection{Break through the Traditional Limitations and Be Used in Interior Design}

At present, wood carving art is more and more widely used in interior design, and has been spread in every corner of the space. Ceiling, beams and columns, interior space partition, partial decoration of furniture, interior structural details and door and window decoration give off unique charm. In terms of interior decoration, the trend of the new era is grasped by combining the use needs and aesthetic concepts of modern people, so that the modeling and application of wood carving can keep pace with the times. Wood carving art has been innovated in the inheritance and breakthrough in the innovation. Based on his own design experience and wood carving art in landscape sculpture, the author has made many attempts to integrate modern indoor environment art design with wood carving art.

\section{Application of Wood Carving in Interior Design}

\subsection{Application of Decoration}

The decoration of details is necessary to enrich the style of the whole interior design. Some small decorations play a great role in setting off the whole decorative style. Without the decoration of indoor crafts, it is impossible to create a beautiful and elegant indoor environment [8]. In today's impetuous material society, people are pursuing a higher level of spiritual world with feelings and interests, instead of the gorgeous and valuable ornaments. Wood carving works well inhe- 
rit the characteristics of Chinese traditional culture, in which most of the carving elements are animal and plant patterns, which have an ancient flavor.

\subsection{Application of Partition}

As people's pursuit of the spiritual world continues to improve with the progress and development of the times, wood carving art is more favored by people. Due to the unique decorative role of wood carving in interior design, it is used in more and more places. The reason why wood carving partition is used in the space design is not to completely separate the two spaces, but to make the two spaces reach an artistic state of separation but still connected, so as to render a unique Chinese flavor. In addition to showing the atmosphere and stability of the interior decoration of the building, it can also show the classical and implicit beauty of Chinese art and create a good space atmosphere [8].

\subsection{Application of Furniture}

As one of the important carving art in China, wood carving is a kind of artworks with exquisite craftsmanship and strong national characteristics [9]. Wood carving art is widely used in the modern interior furniture. In different decoration styles, it's necessary to research the application of wood carving elements on the interior space layout and size. Wood-carving furniture could further reflect the continuation of traditional art and the perfect fusion with modern art, so that it is popular in Chinese style and new Chinese style, which is exactly what the two kinds of styles need. The traditional interior furnishings play an important role in the space atmosphere of the Chinese style home, which embodies the temperament and context of the Chinese national cultural in the decoration of interior space [10]. It is also happened in the new Chinese style. Therefore, the wood-carving furniture has the indelible importance for the tonality of these two styles.

Of course, the wood carving elements maybe applied into the other decorative styles more or less, but most of them will add the wood carving elements to the details of the furniture. This kind of local decoration not only could show the beauty of natural materials, but also makes the space atmosphere simple and meaningful. Therefore, whether from the aesthetic form of furniture design or the effect of the space decoration, the wood carving has a high artistic and cultural value in indoor furniture.

\section{Conclusion}

In the contemporary design, culture heritage should be advancing in unison with the innovative design. A scholar Du Wenchao said, "The core of design is to show cultural characteristics. Once the characteristics are lost, the value of design would be lost." [11] The Chinese traditional culture contained in wood carving is a profound embodiment of culture and characteristics. At the same time, it is a kind of natural feeling that the people in the contemporary urban life 
are pursuing. Therefore, the author thinks that, it's suggested that the application of wood carving on interior space should inherit its national characteristics and cultural connotation, and combine the pattern and modeling of wood carving with modern design, so that wood carving technology can be innovated on the basis of inheritance, and create a perfect end for the interior space design.

\section{Conflicts of Interest}

The authors declare no conflicts of interest regarding the publication of this paper.

\section{References}

[1] Wang, X.R. (2015) Research on the Application of Sculpture Art in Indoor Environmental Art. Hebei Normal University, Shijiazhuang.

[2] Chen, G.J. (2020) Application of Minnan Ancient Cuo Wood Carving in Interior Decoration Design. Design, 33, 44-46. https://doi.org/10.1007/s12273-019-0596-3

[3] Hong, L.L. (2020) Application of Dongyang Wood Carvings in New Chinese Interior Design. Industrial Design, No. 6, 153-154.

[4] Luo, H.W. (2020) Exploration on the Application of Traditional Wood Carving Art in Modern Interior Design. Modern Business Industry, 41, 214.

[5] Shi, L. (2020) Research on the Application of Traditional Wood Carving Art in modern Interior Design. Ju She, No. 2, 102.

[6] Song, X.L. (2019) Research on the Application of Traditional Wood Carving Art in modern Interior Design. Ju She, No. 32, 119.

[7] Han Dian Website. https://www.zdic.net/hans/\%E5\%A5\%91\%E5\%90\%88

[8] Xiang, L.C. (2015) Application of Traditional Chinese wood Carving Art in Interior Design. Yihai, No. 12, 65-66.

[9] Chen, L. (2014) Exploration and Analysis of the Application of Wood Carving Art in Furniture Carving and Decoration. Modern Decoration (Theory), No. 9, 130-131.

[10] Wang, D.L. (2015) On the Application of Wood Carving Furniture in Modern Interior Decoration Design. Modern Decoration (Theory), No. 7, 40-41.

[11] Du, W.C. (2008) Research on Traditional Wood Carving Culture and Art and its Application in Interior Design. Nanjing Forestry University, Nanjing. 